\title{
The Teaching Methods in Translation Courses: E-Learning Resources
}

\author{
Mohammad Iman Askari ${ }^{1, *}$ and Jahanbakhsh Nikoopour ${ }^{2}$ \\ ${ }^{1}$ Department of English Language, Shahryar Branch, Islamic Azad University, Shahryar, Iran \\ ${ }^{2}$ Department of English Language Teaching, North Tehran Branch, Islamic Azad University, Tehran, Iran \\ "Corresponding author: Department of English Language, Shahryar Branch, Islamic Azad University, Shahryar, Iran. Tel: +98-9126054144, Email: miman.askari@gmail.com
}

Received 2018 May 19; Revised 2019 January 14; Accepted 2019 January 16.

\begin{abstract}
Context: This study was carried out during the second semester of academic year 2017-2018 at the Islamic Azad University of Tehran, North and South branches, aiming at providing a description of the attitudes of English-major students towards the teaching methods in translation courses (TCs).

Evidence Acquisition: A multi-item Likert-scale questionnaire was developed based on the principles applied in the three traditional, complex and modern methods of teaching for collecting research data. Cronbach's alpha was used for estimating the reliability of the items. Besides, experts' judgment and item analysis were used for the coverage and relevance of content and construct validity, through which a questionnaire with 32 items was developed. The number of participants was determined based on the margin of error (5\%) and 95\% confidence level for the population size of 140 . Accordingly, the required sample size for the study was calculated at 100. The respondents were randomly selected from the population and were homogenized by the results obtained from the Preliminary English Test (PET). The students were at intermediate level of English proficiency with the mean score of 16.18 and standard deviation of 31 .

Results: According to the participants' viewpoints, although all the methods were common, but modern methods challenged the traditional and complex methods by emphasizing on the necessity of incorporation of the principles for assuring quality and relevance by applying various study resources like e-learning facilities.

Conclusions: It is not possible to consider any of the methods as superior, however, it is necessary to further adapt the principles included in any of the three methods to the local and novel needs. In other words, gaining the viewpoints of learners as the final recipients of the methods would be helpful for instructors via enabling them to find out how subtle variations in methods might lead learners to various directions depending on their attitudes and the use of e-learning resources, based on which the necessary adaptations are made in the application of methods.
\end{abstract}

Keywords: English-Major Students, Methods of Teaching Translation, Translation Courses

\section{Context}

Currently, translation courses (TCs) are among the academic resources which have a crucial role in paving the grounds for other resources and equip English-major students with an updated knowledge of several different fields.

Studying translation within a functional perspective, Holmes (1) proposed a framework for translation studies in an attempt to develop a map for the field via focusing on what is called 'missing link' of Holmes' map of translation studies. The gap was training in translation, which could be the basis for the evolution of translation studies (2) and other works like Toury's (3) map of translation studies.

Besides all the efforts made for recognizing the resources for translation training and its consequent effects on teaching methodologies, it is valuable to refer to the present age of digital technology which has brought fundamental changes to translation studies, through which the activities involved in translation training have been changed dramatically. These changes are shaped via students' access to many different resources of science provided by the internet infrastructures (4).

Incorporating high-tech resources in the teachinglearning process, modern didactics significantly compensates for the lack of materials for trainers and trainees in translation. However, the ever-increasing interest in electronic resources for translation studies has led instructors to benefit from the advantages of large multifunctional and freely available databases found in a simple survey on the web. The use of such resources in the professional sphere and corpora is becoming increasingly common in the academic curriculum of higher education insti- 
tutions (5-8). However, it is important to consider the barriers to using online resources in the process of developing translation proficiency via applying different methods of teaching since they are very different from one another. However. answering to the questions like "can translation be taught?", "can it be taught through perceptions, rules, and principles?", and "can it only be taught through doing it and getting feedback?" might reveal the importance of the barriers mentioned by the scholars who proposed corpus-informed didactic resources to make the teachinglearning processes active and natural (6). In this view, due to the importance of e-learning resources in the modern perspectives of teaching methodologies, it is noteworthy to consider these resources as one of the determining factors for both language and translation learning.

Another issue intertwined with the importance of TCs is the teaching methods used by instructors to teach translation to learners. Therefore, due to the essential role of TCs in educational contexts, it is valuable to examine the current methods of teaching TCs proposed by Alekseeva (9). Besides traditional and complex methods of teaching translation, Alekseeva (10) proposed modern methods. In her opinion, these methods are the specific branch of translation studies which challenge previous methods of teaching, where text was treated as an objective phenomenon and translation was defined as dealing with signs of an original text.

Most recent studies on teaching translation methods have focused on mere teaching methods, neglecting translation learning techniques. By considering this fact, Garant (11) discussed Nord's model of translationoriented text analysis as well as the process-oriented and the competence- and skill-led approaches to teaching translation.

Methods of teaching translation were also considered as a sub-branch of second language acquisition by pointing out the input-based systems for the assessment of students' translation practices or the output-based systems to focus on the feedback provided for the learners including Krashen's (12) monitor model and Swain's (13) comprehensible output hypothesis. Thus, the commonalities existing in all methods of teaching TCs have made it necessary to find out more about their effectiveness by applying different perspectives to educational studies and designs. In this view, according to O'Donoghue and Punch (14), data could be checked and verified by multiple sources of data collection via qualitative and quantitative procedures to reach the intended regularities in the research data, the results of which might be valuable for applying better teaching practices in translation classes.

Thus, conducting studies to provide the instructors with the learners' attitudes about the translation teach- ing methods is significant since their results could provide instructors with solutions for the challenging aspects of teaching.

The present study was carried out during the second semester of academic year 2017-2018 at the Islamic Azad University of Tehran, North and South branches' College of Foreign Languages to provide a description of the attitudes of English-major students towards the teaching methods in TCs through providing answers to the following research questions:

Major question: How differently TCs are taught to Iranian English-major students with respect to the different methods of teaching including traditional, complex and modern methods?

Minor question 1: What is Iranian English-major students' perception of the significance and justification of traditional methods of teaching TCs?

Minor question 2: What is Iranian English-major students' perception of the significance and justification of complex methods of teaching TCs?

Minor question 3: What is Iranian English-major students' perception of the significance and justification of modern methods of teaching TCs?

Minor question 4: What is Iranian English-major students' perception of the significance and justification of e-learning resources for teaching TCs?

\section{Evidence Acquisition}

\subsection{Participants}

In this descriptive study, the participants were Englishmajor students studying at Islamic Azad University of Tehran, North and South branches' College of Foreign Languages. The students were in their third and fourth academic semesters, to ensure their acquaintance with the basic translation principles via the necessary translation courses in the approved English major curriculum.

The number of participants was determined based on the margin of error (5\%) and 95\% confidence level for the population size of 140 . Accordingly, the required sample size for the study was 100 . The participants were randomly selected from the population and were homogenized by the results obtained from the preliminary English test (PET) provided by Cambridge English Language Assessment. After the administration of PET, the students whose scores fell within the range of one standard deviation above and below the mean formed the main participants of the study. The participants were at intermediate level of English proficiency and were both male and female students whose first language was Persian. The mean PET score was $16.18 \pm 0.31$. 


\subsection{Instruments}

\subsubsection{Language Proficiency Test}

PET, developed by Cambridge English Language Assessment, was used for selecting homogenous participants.

\subsubsection{Questionnaire}

Since a questionnaire was used as the instrument for data collection, after developing the items, the instrument underwent several piloting studies for estimating the reliability and validity of the items. Item analysis with Cronbach's alpha, as a measure of internal consistency, was administered for estimating the reliability of the items. The item analysis results helped the researcher to understand how well a set of items measured a characteristic (or construct). As a result, the researcher identified the problematic items before the final administration. For this purpose, the reliability of the questionnaire's items was examined based on the data gathered from the pilot study and computed through SPSS software. The items resulting in a lower reliability coefficient (lower than 0.7) were deleted, which included 3 out of 35 items scoring a lot higher or lower than other items. The overall Cronbach alpha reliability coefficient of the questionnaire was 0.934 before deleting the problematic items, which reached to 0.935 and 0.939 after estimating the Cronbach's alpha coefficient by SPSS version 21. In addition, the face validity of the items regarding the readability, feasibility, clarity of wording as well as layout and style of items were examined.

Experts' judgment was also used for the content coverage and relevance in content validity. In addition, for examining the construct validity of the items, item analysis was used as a method to empirically determine the interrelationships among items and to identify the clusters of items that share sufficient variation to justify their existence as a factor or construct to be measured by the instrument. In doing so, the various items of the questionnaire were gathered into common factors and labeled by traditional, complex and modern components of the questionnaire. Through this process, further modifications were made to the items before the final administration of the questionnaire among the samples.

Cronbach's alpha was used for estimating the reliability of the items, based on which the overall Cronbach's alpha reliability coefficient of the questionnaire estimated at 0.934 before deleting the problematic items and reached to 0.935 and 0.939 after estimating the Cronbach's alpha coefficient. Besides, experts' judgment and factor analysis were used for the coverage and relevance of the content and construct validity for which the average CVR of the items was $0.6>0.42$ and the average CVI of the items was $0.8>0.79$. The Likert-scale values for each ques- tion included 1, 2, 3, 4, and 5 standing for the students' responses to the items as strongly agree, agree, neutral, disagree, and strongly disagree. These values were applied to all questionnaire items.

\subsection{Design}

The study as a subset of descriptive studies in humanities, intended to provide a description of the trends, attitudes and opinions of English-major students about the common teaching methods applied in TCs. Thus, by delimiting the study to theme-based quality, relevance to course evaluation, and availability of e-learning resources, the three traditional, complex and modern methods of teaching TCs were investigated through a cross-sectional survey study.

The reason for choosing the survey study was to investigate the different perceptions of students obtained from their responses to the questionnaire items. It is also important to recognize that "the survey approach is a research strategy, not a research method" (15).

\subsection{Procedure}

As a survey study for which a questionnaire was required for the data collection from among homogenized participants, a questionnaire was developed and modified through pilot studies in order to estimate the reliability and validity of the items. Afterwards, the final questionnaire with 32 items was administered among the participants. The respondents were taught how to answer the items in their English translation classes via a brief description of the methods used for developing the items. After the students completed and submited the questionnaire to their instructor, the students' responses were analyzed through SPSS software.

\section{Results}

\subsection{Data Analysis}

\subsubsection{Reliability Indices for the Questionnaire's Items}

To ensure the reliability of the questionnaire, the items were divided into three basic components based on different characteristics for grasping the students' viewpoints towards the appropriateness and use of the current teaching methods and their relevant consequences for learning procedures. Reliability analysis was carried out on the perceived task values scale comprising 32 items. The results of Cronbach's alpha revealed the acceptable reliability ( $\alpha$ $=0.934)$ of the questionnaire based on the standardized items analysis in the pilot. Most items appeared to be worthy of retention as their deleting would result in a decrease 
in alpha, with the exception of items 6 (in traditional methods) and 32 (in modern methods) which would increase alpha to 0.935 as well as item 27 (in complex methods) which would increase the alpha to 0.939 . Thus, the removal of the items was considered for the acceptable reliability, and data were gathered via the reliable questionnaire including 32 items.

\subsection{Items Data Analysis}

\subsubsection{Items Data Analysis for the Major Research Question}

The major research question was concerned with how differently TCs are taught to English-major students with respect to the different methods of teaching including traditional, complex and modern methods as well as other common methods.

The results presented that all the mentioned methods were common in teaching TCs. Overall, 37\% of the participants indicated the use of traditional methods through focusing on the specific field, text analysis, translation equivalents and authoritarian-creative perspectives. Further, according to the students' viewpoints, $26 \%$ of them had experienced translation training via complex methods and utilizing preparatory, basic, and training stages. Besides, modern methods were also common in teaching TCs, since $22 \%$ of the responses were devoted to the application of modern methods via specialized text translation training. The rest of the students were trained through other methods of teaching TCs, which consisted of $15 \%$ of the total participants.

\subsubsection{Items Data Analysis for the Minor Research Question 1}

The frequencies and percentages of the students' responses to the items regarding the first branch of traditional methods of teaching TCs are shown Table 1.

As the responses to the first question indicated, $66 \%$ of the students believed that the training which began with studying and teaching the vocabularies of a specific field and giving equivalences in the language of translation was useful in the first sub-branch of traditional methods.

Besides, $59 \%$ of the participants asserted that since the methods proceeded with the complicated grammatical structures of specialized written texts, the learners were able to acquire translation within specific fields.

To mention the disadvantages of the first sub-branch of traditional methods of teaching, it should be noted that nearly half of the learners ( $44 \%$ ) pointed out the unawareness of the learners of the stylistic peculiarities.

Through investigating the second sub-branch of traditional methods, it was revealed that $60 \%$ of the participants believed in appropriateness of text analysis that resulted in identifying the features of texts and principal aspects in training languages and translation within higher

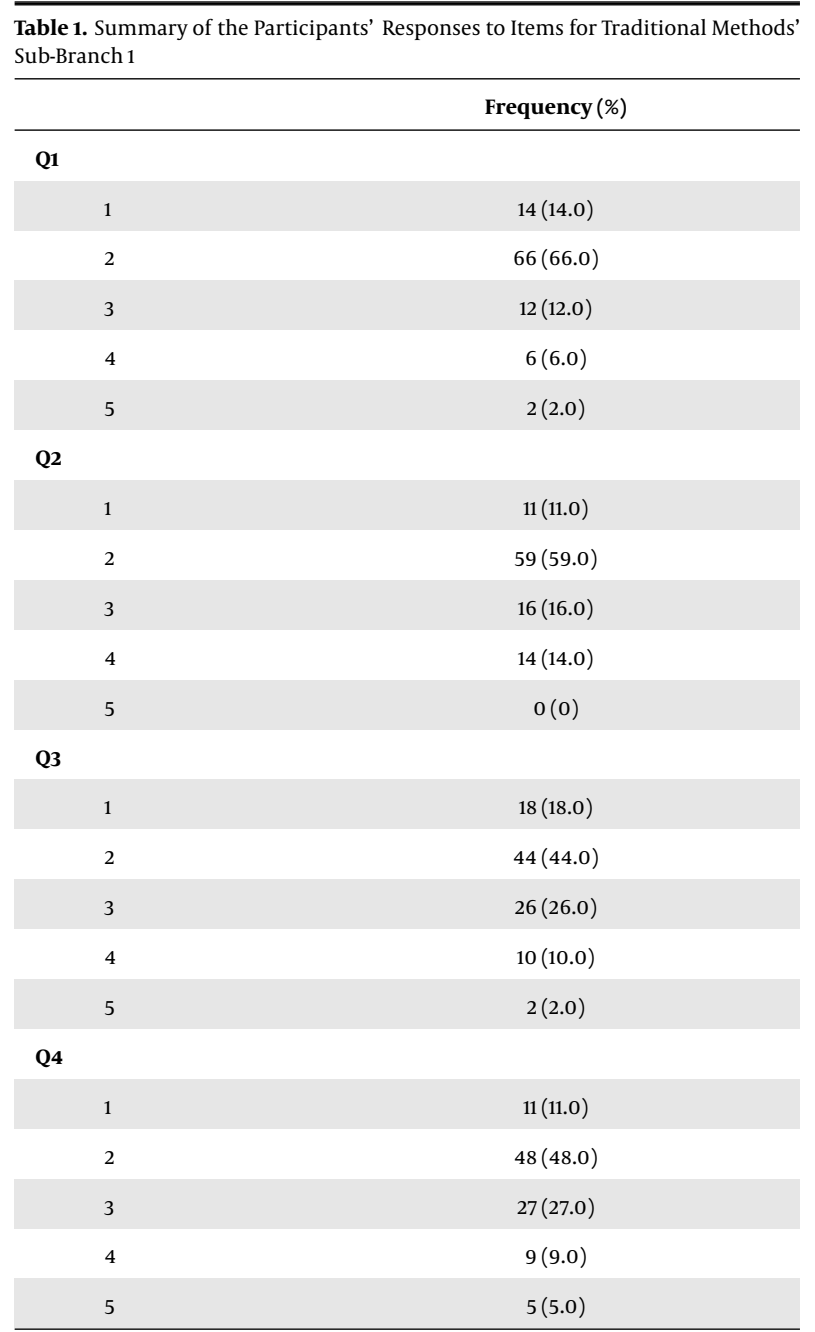

education context, which may result in intuitive choices in a translation work. On the other hand, based on more than $51 \%$ of the participants' viewpoints, the method was not successful in considering the features of the text as complete substance and required additional drawbacks to the processes in translation. Thus, the features such as type of the text, sphere of application, and recipients might be neglected. Also, according to responses provided for item 8 , $58 \%$ of the participants expressed their positive viewpoints towards the second sub-branch of traditional methods.

The third sub-branch of traditional methods applied by instructors of TCs consisted of finding all the existing translation equivalents. Via applying this method, finding many equivalents for a single word might be timeconsuming, but upon taking into consideration the type of the text, word compatibility, and shades of meaning, the variety of equivalents invariably reduced. Accordingly, the role of text's type was provided as the questionnaires's 
item, based on which $52 \%$ of the participants confirmed its importance.

Finally, almost half of the participants (49\%) considered the sub-branch as an extensive practice of active vocabularies in a translation task without much concern to make intuitive choices in translation.

The discussion on the traditional methods was finalized by the responses provided for item 17 aimed at grasping the English-major students' overall perspectives towards traditional methods of teaching TCs. This item revealed that more than $50 \%$ of the participants believed in the inappropriateness of traditional methods of teaching TCs, despite its advantages for beginners and basic stages of translation training.

\subsubsection{Items Data Analysis for the Minor Research Question 2}

The second minor research question of the study was proposed to find out the English-major students' perceptions about the complex methods of teaching applied in TCs, for which a total of eight items was provided.

The first item of the questionnaire for the complex methods asked for the participants' general viewpoints about the helpfulness of methods in teaching translation, in response to which $60 \%$ of the responses agreed with the concept as shown in Table 2.

\begin{tabular}{|c|c|}
\hline & Frequency (\%) \\
\hline \multicolumn{2}{|l|}{ Q18 } \\
\hline 1 & $9(9.0)$ \\
\hline 2 & $51(51.0)$ \\
\hline 3 & $24(24.0)$ \\
\hline 4 & $14(14.0)$ \\
\hline 5 & $2(2.0)$ \\
\hline
\end{tabular}

As the methods composed of three stages and each stage must be subjected to investigation for the applicability of the methods, some more items were devoted to each stage. The study focused on the preparatory, basic, and training stages in teaching TCs that were pursued in traditional methods to some extent.

According to the students' responses to the items provided for the basic stage of training (i.e., 22, 23, and 24), approximately $50 \%$ of the respondents expressed their positive attitudes towards the importance of the basic stage in complex methods of teaching TCs as a learner-centered approach to teaching.

The last items (i.e., 25 and 26) of the complex methods were provided to grasp the general perspectives of the participants towards the processes and properness of the methods, in response to which about $50 \%$ of the respondents believed that at the beginning of the basic stage of training, it is the teacher who should edit students' translations; later on, the students were to edit one another's translation, and finally, students should edit their own translations and read them aloud to the audience, which was considered as the most complicated task in TCs. Thus, the steps in acquisition may result in a better translation practice.

Also, investigating the processes applied in complex methods, more than $50 \%$ of the participants declared their positive attitudes towards the applicability and properness of training translation via complex methods. The summary of the participants' responses to the items is shown in Table 3.

Table 3. Summary of the Participants' Responses to the Basic Items in Complex Methods

\begin{tabular}{|c|c|}
\hline & Frequency (\%) \\
\hline \multicolumn{2}{|l|}{ Q25 } \\
\hline 1 & $10(10.0)$ \\
\hline 2 & $43(43.0)$ \\
\hline 3 & $32(32.0)$ \\
\hline 4 & $12(12.0)$ \\
\hline 5 & $3(3.0)$ \\
\hline \multicolumn{2}{|l|}{ Q26 } \\
\hline 1 & $9(9.0)$ \\
\hline 2 & $46(46.0)$ \\
\hline 3 & $28(28.0)$ \\
\hline 4 & $12(12.0)$ \\
\hline 5 & $5(5.0)$ \\
\hline
\end{tabular}

\subsubsection{Items Data Analysis for the Minor Research Question 3}

In order to answer the third question of the study, items 27,28 and 29 were provided in the survey's questionnaire focusing on the limitations imposed by the traditional methods and the contemporary views of modern methodologies in teaching TCs. Modern methods via ignoring the signs and symbols of a language put emphasis on other principles and statements for teaching. The issue was asked from the students by item 28 , through which more than $50 \%$ of the respondents confirmed the existence of the claimed statements in modern methods. More than $50 \%$ of the respondents believed in the vital role of these methods in teaching TCs. The summary of the participants' responses to the items is presented in Table 4. 


\begin{tabular}{|c|c|}
\hline & Frequency (\%) \\
\hline \multicolumn{2}{|l|}{ Q27 } \\
\hline 1 & $8(8.0)$ \\
\hline 2 & $48(48.0)$ \\
\hline 3 & $23(23.0)$ \\
\hline 4 & $17(17.0)$ \\
\hline 5 & $4(4.0)$ \\
\hline \multicolumn{2}{|l|}{ Q28 } \\
\hline 1 & $14(14.0)$ \\
\hline 2 & $43(43.0)$ \\
\hline 3 & $23(23.0)$ \\
\hline 4 & $17(17.0)$ \\
\hline 5 & $3(3.0)$ \\
\hline \multicolumn{2}{|l|}{ Q29 } \\
\hline 1 & $14(14.0)$ \\
\hline 2 & $46(46.0)$ \\
\hline 3 & $24(24.0)$ \\
\hline 4 & $13(13.0)$ \\
\hline 5 & $3(3.0)$ \\
\hline
\end{tabular}

\subsubsection{Items Data Analysis for the Minor Research Question 4}

The fourth minor research question of the study was proposed to find out the English-major students' perceptions on the significance and justification of e-learning resources in methods of teaching TCs, for which a total of three (i.e., 29, 30 and 31) items were provided. These items focused on the students' attitudes towards the role of elearning resources in the three methods of teaching TCs. In this regard, more than $50 \%$ of the participants declared that e-learning resources were significant in applying all the three methods of teaching TCs. In other words, the respondents confirmed that the existence of e-learning resources is quite influential in the applicability of the methods and thus, they are beneficial in learning TCs.

The summary of the participants' responses to the items is demonstrated in Table 5.

\section{Conclusions}

The findings of this study confirmed that nearly all the considered methods, besides further creative activities through other methods, were applied in the Iranian educational settings via applying various learning resources including online and electronic materials.

Teaching translation has been regarded as one of the major topics of translation studies, which could target

\begin{tabular}{|c|c|}
\hline & Frequency (\%) \\
\hline \multicolumn{2}{|l|}{ Q30 } \\
\hline 1 & $8(8.0)$ \\
\hline 2 & $48(48.0)$ \\
\hline 3 & $23(23.0)$ \\
\hline 4 & $17(17.0)$ \\
\hline 5 & $4(4.0)$ \\
\hline \multicolumn{2}{|l|}{ Q31 } \\
\hline 1 & $14(14.0)$ \\
\hline 2 & $43(43.0)$ \\
\hline 3 & $23(23.0)$ \\
\hline 4 & $17(17.0)$ \\
\hline 5 & $3(3.0)$ \\
\hline \multicolumn{2}{|l|}{ Q32 } \\
\hline 1 & $14(14.0)$ \\
\hline 2 & $46(46.0)$ \\
\hline 3 & $24(24.0)$ \\
\hline 4 & $13(13.0)$ \\
\hline 5 & $3(3.0)$ \\
\hline
\end{tabular}

not only future professional translators but also advanced language learners. The following famous map of translation teaching studies was provided by Toury (3). According to Toury also refers to the reciprocal nature of relations between DTS and Translation Theory, since "carefully performed studies into well-defined corpuses, or sets of problems constitute the best means of testing, refuting, and especially modifying and amending the very theory, in whose terms research is carried out" (Toury 1995) (3).

Although all the mentioned studies and the related tools can be the convenient guides during the translation process for the terminology and documentation purposes, but it is also crucial to have a deep understanding of students' convenience with the procedures within a specific method of teaching that might result in the best use of such guides and techniques and encouragement of students to translate in a real-life experience or work in a collaborative project through applying the accessible resources.

The methods also put emphasis on form-content relations for further adjustments that draw learners' attention to the polysemantic nature of a translation task and cooperative learning procedure with the absence of intuitive choices in finding equivalents. In this context, students might be able to find as many equivalents as possible for 
a specific term, for which instructors of TCs, according to the students' viewpoints, are required to be equipped with both principles of translation and experts' knowledge. Accordingly, further to the participant's perspectives, a combination of different sub-branches of traditional methods seem to be essential in the first steps of training to ensure the quality and relevance of methods to the related needs.

The need for a combination of different teaching techniques was investigated through the items provided for the complex methods of teaching TCs. The items were provided based on the different and important stages of training in the methods including the preparatory and basic stages, which were new in comparison with traditional methods.

Based on the participants' views, complex methods were more helpful through providing the stages in which different text genres, critical reading, analysis and synthesis were required to assure the quality and relevance of teaching methods. However, finding equivalents was based on text analysis and helped translators to delimit the scope of analytical research in a two-way interaction between the instructor and student.

The concept of ideal translation was also achievable through the methods, and this factor was considered as the suitable guide during the translation training processes, but it might deemphasize the cooperative learning procedure.

However, the case was changed in modern methods by pointing out the efficacy of the methods in the context of Iran. In addition to challenging the previous methods of teaching TCs, the items in modern methods disclosed the limitation of the other methods and the necessity for their incorporation into modern perspectives of teaching TCs for assuring the quality and relevance to the learners' needs. . the evidence to such a claim is the use of modeling and consequent transfer of a complex-structured in translating a text.

Concerning the pedagogical implications of this study, it is noteworthy to mention the fact that in almost all higher education settings, the concepts of quality and relevance could be investigated through the teaching methods applied in various programs and fields of study. Although a variety of methods could be considered for every specific course, the resources which are considered as the platform of the methods seem to be vital for optimal performance. Thus, a specific method's principles might be considered as the basis for other methods within the specific educational contexts for teaching and learning. The examples of such cases are presented as follows:

(1) The procedure of finding equivalents emphasizes in the traditional methods;

(2) Syntactic features of various text types which should be included in any method of teaching;

(3) The combination of various skills was not enough in itself since translation is a creative process;

(4) Overlapping of different methods in the major principles;

(5) Application of various resources for the optimal implication. However, e-learning resources seem to be of further assistance in justifying the methods' deficiencies due to their availability and variety.

The results of the present study can be used by practitioners and researchers in language teaching and translation studies via enabling them to find out how some subtle variations might lead learners to the right or wrong directions in learning the concepts depending on the content provided by the educational context and curriculum.

Regarding the limitations of this study, it should be noted that teaching translation was considered to be a novel field of study and the teaching methods investigated were limited to the general classification of traditional, complex, and modern methods of teaching. Besides, the general population from which the participants were selected was limited to students in their third or fourth academic semesters for ensuring their basic familiarity with the principles of translation.

\section{Footnotes}

Authors' Contribution: Mohammad Iman Askari devised the study concept, designed the study, supervised the intervention, data collection and analysis, participated in the coordination of the study, and critically revised the manuscript. Jahanbakhsh Nikoopour also contributed in all the mentioned steps.

Conflict of Interests: It is not declared by the authors.

Ethical Considerations: Informed consent was obtained from all the participants included in the study, that consisted of faculty members and students at Islamic Azad University of Tehran, Faculty of Foreign Languages.

Funding/Support: The Authors did not receive any support or funding for this article.

\section{References}

1. Holmes JS. The name and nature of translation studies. In: Venuti L, editor. The translation studies reader. London: Routledge; 1988. p. 17285.

2. Munday J. Introducing translation studies: Theories and applications. London: Routledge; 2001.

3. Toury G. Descriptive translation studies and beyond. Philadelphia: John Benjamins; 1995.

4. Cronin M. Translation in the digital age. London: Routledge; 2012.

5. Pastor GC. Investigar con corpus en traducción: Los retos de un nuevo paradigma. Frankfurt am Main, Germany: Peter Lang; 2008. Spanish. 
6. Beeby A, Rodríguez-Inés P, Sánchez-Gijón P. Corpus use and translating: Corpus use for learning to translate and learning. Amsterdam: John Benjamins; 2009.

7. Gallego Hernándes D. Traducción económica y corpus: Del concepto a la concordancia. Aplicación al Francés y al Espa-Ol. Alicante: Publications Service of the University of Alicante; 2012. Spanish.

8. Robinson D. Becoming a translator: An introduction to the theory and practice of translation. New York: Routledge; 2012.

9. Alekseeva I. Professional training for translators: A textbook on interpretation and written translation for teachers and translators. Petersburg: Sankt; 2000.

10. Alekseeva L. Methodology for teaching written specialized text translation. Vestnik: Perm University Press; 2010.
11. Garant M. Current trends in translation teaching and learning. Helsinki: University of Helsinki Press; 2010.

12. Krashen SD. Principles and practice in second language acquisition. $\mathrm{Ox}$ ford: Pergamon Press Inc; 1982.

13. Swain M. Communicative competence: Some roles of comprehensible input and comprehensible output in its development. In: Gass $\mathrm{S}$, Madden C, editors. Input in second language acquisition. New York: Newbury House; 1985.

14. O'Donoghue T, Punch K. Qualitative educational research in action: Doing and reflecting. London: Routledge; 2003.

15. Denscombe M. The good research guide: For small-scale social research projects. Buckingham: Open University Press; 1998. 